To render the results as certain as possible, portions of the mineral were carefully heated in sealed tubes with a solution of copper sulphate, as had been done with marcasite. The evidence gathered in this way corroborated the first experience and it can safely be asserted that chalcopyrite contains all of its iron in the ferrous form, and that the mineral is, perhaps, nothing more than a substituted marcasite, in which copper has replaced its equivalent of iron.

Untversity of PenNSyluania.

\title{
ON TRIPHENYLCHLORMETHANE.
}

BY M. GOMBERG.

Received January 72 , Igot.

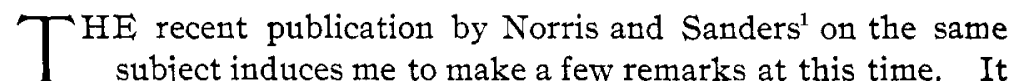
is far from my intention to enter into any controversy whatever. I merely wish to call attention to the following few points :

( I) My paper on "Triphenylchlormethane"' was first presented by me at the Columbus Meeting of the American Association for the Advancement of Science, August, I 899. Norris and Sanders state that they have been at work on this subject for about a year. Hence this subject must have been undertaken by them after my paper was presented. It was, however, entirely natural that they should have overlooked the first mention of my paper, since it was given in the Proceedings ${ }^{3}$ only by title.

(2) The difference in procedure between my method and that of Norris and Sanders consists in that the latter used, instead of benzene as a solvent, carbon disulphide,- - a diluent first introduced by Anschütz for Friedel and Crafts' reaction in general. The application of this solvent in the present instance enabled Norris and Sanders to isolate the important intermediate product, the double salt of aluminum chloride and triphenylchlormethane, which was not obtained by me at all.

(3) Norris and Sanders state ${ }^{5}$ that the action of sodium upon triphenylchlormethane is entirely negative, even on two weeks'

\footnotetext{
1 Am. Chem. J., 25, 54 .

2 This Journal, 22, 752 .

3 Proceedings American Association for the Advancement of Science, 48, 152 (1899).

4 Ann. Chem. (Liebig), 235, 34I.

5 Loc. cit., p. 59.
} 
contact in ether. Only on the addition of brombenzene to the above mixture did a reaction take place. One of the several products was a body free from halogen, yet on analysis the carbon and hydrogen did not add up to Ioo per cent. The fact that " this compound resembles closely in melting-point, chemical composition, and solubility" the substance (the peroxide) described by $\mathrm{me}^{1}$ shows that it is an oxygen body. One fails to see, however, how Norris and Sanders "discovered that an oxygen compound was formed as the result of the action of sodium on a mixture of triphenylchlormethane and brombenzene." No evidence is given that they excluded all oxygen-carrying reagents, such as sodium oxide, and that this was not the cause of the formation of that body, or that they worked in an atmosphere free from oxygen, and in this way established the non-formation of that body under these conditions. Furthermore, if the substance is really identical with the peroxide mentioned, it is not the result of the action of sodium upon a mixture of the two halogen compounds, but is formed by action of the atmospheric oxygen upon the unsaturated hydrocarbon (triphenylmethyl) which must have resulted in some way from the action of sodium upon triphenylchlormethane alone. " The reaction must, therefore, be analogous to that described by me for other metals: silver, zinc, and mercury. Only these three metals, in addition to the unsatisfactory results with sodium, are mentioned in my preliminary paper. Other metals, however, and different solvents, have also been tried and are being studied at present. Norris and Sanders now "propose to investigate the action of sodium on ethereal solutions of triphenylchlormethane of varying concentrations." I regret that having cleared up the difficult part of the problem (the action of metals upon triphenylhalogenmethanes) I am not to have, as it appears from Norris' publication, this field to myself for a while longer. It was stated ${ }^{3}$ in my preliminary paper that only about two-thirds of the theoretical quantity of the unsaturated hydrocarbon is formed. The nature of the other products is being studied and $I$ find that this varies according to the metal and solvent employed.

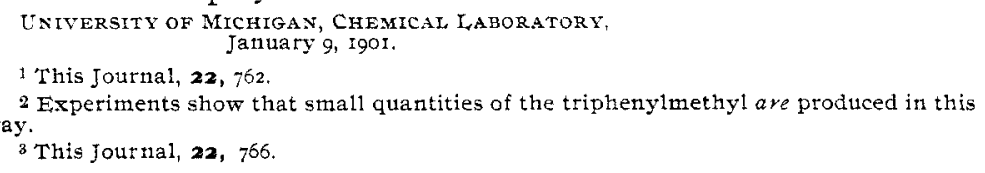

